\title{
Tuberculosis mortality in HIV-infected individuals: a cross-national systematic assessment
}

\author{
Christopher Au-Yeung' \\ Steve Kanters' \\ Erin Ding' \\ Philippe Glaziou ${ }^{2}$ \\ Aranka Anema ${ }^{1,3}$ \\ Curtis L Cooper ${ }^{4}$ \\ Julio SG Montaner ${ }^{1,3}$ \\ Robert S Hogg 1,5 \\ Edward J Mills ${ }^{1,6}$ \\ 'BC Centre for Excellence in \\ HIVIAIDS, Vancouver, Canada; \\ ${ }^{2}$ Stop TB Department, World Health \\ Organization, Geneva, Switzerland; \\ ${ }^{3}$ Faculty of Medicine, University of \\ British Columbia, Vancouver, Canada \\ ${ }^{4}$ The Ottawa Hospital Division of \\ Infectious Diseases; ${ }^{5}$ Faculty of Health \\ Sciences, Simon Fraser University, \\ Burnaby, Canada; ${ }^{6}$ Faculty of Health \\ Sciences, University of Ottawa, \\ Ottawa, Canada
}

Correspondence: Edward J Mills Faculty of Health Sciences, University of Ottawa, 43 Templeton St, Ottawa KIN 6XI, Canada

$\mathrm{Tel}+\mathrm{I} 7783178530$

Fax + I 6048069044

Email edward.mills@uottawa.ca
This article was published in the following Dove Press journal:

Clinical Epidemiology

19 January 2011

Number of times this article has been viewed

Objective: Tuberculosis (TB) is a leading cause of death in human immunodeficiency virus (HIV)-positive individuals. We sought to compare mortality rates in TB/HIV co-infected individuals globally and by country/territory.

Design: We conducted a cross-national systematic assessment.

Methods: TB mortality rates in HIV-positive and HIV-negative individuals were obtained from the World Health Organization (WHO) Stop TB department for 212 recognized countries/territories in the years 2006-2008. Multivariate linear regression determined the impact of health care resource and economic variables on our outcome variable, and TB mortality rates.

Results: In 2008, an estimated 13 TB/HIV deaths occurred per 100,000 population globally with the African region having the highest death rate ([AFRH] $\geq 4 \%$ adult HIV-infection rate) at 86 per 100,000 individuals. The next highest rates were for the Eastern European Region (EEUR) and the Latin American Region (LAMR) at 4 and 3 respectively per 100,000 population. African countries' HIV-positive TB mortality rates were 29.9 times higher than non-African countries (95\% confidence interval [CI]: 16.8-53.4). Every US\$100 of government per capita health expenditure was associated with a $33 \%$ (95\% CI: $24 \%-42 \%)$ decrease in TB/HIV mortality rates. The multivariate model also accounted for calendar year and did not include highly active antiretroviral therapy (HAART) coverage.

Conclusions: Our results indicate that while the AFRH has the highest TB/HIV death rates, countries in EEUR and LAMR also have elevated mortality rates. Increasing health expenditure directed towards universal HAART access may reduce mortality from both diseases.

Keywords: tuberculosis, HIV, antiretroviral therapy, mortality

\section{Introduction}

Tuberculosis (TB) and human immunodeficiency virus (HIV) are two devastating global infectious diseases. TB is one of the deadliest diseases of the 20th century and continues to claim millions of lives. ${ }^{1-4}$ The global HIV epidemic also continues to claim many lives, despite the global scale-up of antiretroviral (ARV) therapy. In 2008, an estimated 33.4 million people worldwide were living with HIV, and 2.7 million were newly infected. More than 25 million people worldwide have died from HIV since the epidemic began. ${ }^{5}$

Immune-suppressed HIV-positive individuals are more likely to become co-infected with $\mathrm{TB},{ }^{6}$ which is a leading cause of death in this population, ${ }^{7}$ especially among those who reside in Sub-Saharan Africa. ${ }^{8,9}$ The dual burden of TB and HIV infection increases the likelihood of dying compared with having either disease separately. ${ }^{10-14}$ Previous studies have examined the effect of TB on mortality in HIV-infected individuals within 
specific cohorts. For example, a recent study of TB patients in Nigeria found that $15.5 \%$ of HIV-positive individuals on treatment died, compared with $3.1 \%$ of HIV-negative individuals. ${ }^{13}$ There remains a dearth of research on global TB mortality in HIV-positive individuals.

The purpose of this analysis was to investigate the global burden of TB incidence and mortality in people with HIV. Our objectives were to determine rates of TB mortality in HIV-positive individuals compared with HIV-negative individuals by World Health Organization (WHO) designated regions, and to assess the effect of health care resources and economic variables on reducing TB/HIV co-infection mortality.

\section{Methods}

\section{Data sources}

The estimated number of TB (all forms) deaths among HIV-positive and HIV-negative individuals, along with health care resources and economic data by country/ territory were gathered from our prospectively maintained Globally Accumulated health Indicator Archive (GAIA) of publicly accessible health statistics for the years 2006-2008. The last available data was from 2008. Source data on TB death rates and incidence per 100,000 general population and the proportion of HIV among TB incident cases originated from statistics produced by the WHO's Stop TB department. The 'Year', 'Region', and 'Percent of HIV-positive new pulmonary smear-positive cases cured' were obtained from WHO's Stop TB department. 'Percent HAART coverage' data were obtained from WHO's Towards Universal Access 2009 report. ${ }^{15}$ 'GDP' (gross domestic product) in current international dollars (PPP, purchasing power parities), and 'Percent of women and men who received HIV testing in the last 12 months and know their results' were obtained from UNDATA. ${ }^{16}$ Data for 'Number of AIDS deaths' were taken from UNAIDS. 'Per capita government expenditure on health at average exchange rate (US\$)' and 'Personal expenditure on health as \% of total expenditure on health' (year 2006 only) were obtained from WHO's World Health Statistics 2009 report. ${ }^{17}$ 'Average exchange rate' specifies the observed annual average rate at which a currency is traded in the banking system. All source data were publicly accessible through the Internet.

All 212 recognized countries and territories listed in the WHO annual TB reports were included and classified into regions based on WHO designation. Regional classification were as follows: AFR, African countries with a low HIV-infection rate (where 'low' refers to a generalized infection rate $<4 \%$ in adults aged $15-49$ years in 2004) $(\mathrm{N}=20$ in 2006-2008); AFRH, African countries with a high HIV-infection rate ( $\mathrm{N}=26$ in 2006-2008); CEUR, Central European region ( $\mathrm{N}=10$ in 2006-2008); EEUR, Eastern European region ( $\mathrm{N}=16$ in 2006-2008); EMR, Eastern Mediterranean region ( $\mathrm{N}=17$ in 2006-2008); EME, established market economies ( $\mathrm{N}=56$ in 2006-2008); LAMR, Latin American region ( $N=31$ in 2006-2008); SEAR, SouthEast Asia region ( $\mathrm{N}=11$ in 2006-2008); and WPR, Western Pacific region ( $\mathrm{N}=25$ in 2006-2008). Mortality rates were available for all countries/territories for each year (2006-2008) and are presented per 100,000 people for each country/territory. Each country's total population size was taken from WHO's Stop TB department statistics. To assess the difference in magnitude of HIV-positive to HIV-negative TB deaths, a ratio of the TB death rate in HIV-positive over HIV-negative individuals was calculated using each country's mortality rates. A regional and global estimate of mortality rates was calculated for each year.

\section{TB/HIV mortality model}

The WHO produces estimates of TB incidence prevalence and mortality that are published in their annual TB report entitled, 'Global Tuberculosis Control: Surveillance, Planning, Financing'. ${ }^{1-3}$ The most up-to-date estimates were based on data collected in 2009. The model involves creating a time-series of country-specific HIV-positive TB incidence distributions. These distributions incorporate two distributions of case fatality rates (in notified and nonnotified cases) among those co-infected with TB/HIV. Using simulations, the incidence rate distributions were multiplied with the case fatality rate distributions. A more detailed description of the changes to the modeling process from previously published 'Global Tuberculosis Control' reports can be found in an update to the 2009 report. ${ }^{18}$

\section{Analyses}

Pearson's correlation coefficient was used to assess the linear relationship between TB death rates in HIV-positive individuals and all explanatory variables aside from year, region, and highly active antiretroviral therapy (HAART) coverage for the years 2006-2008 and for the year 2008 only. All relationships were evaluated graphically, and proper transformations were applied to render them linear. HAART coverage had to be dichotomized. The magnitude and sign of the coefficient represented the strength and direction of the linear relationship. $P$-values were calculated to test whether the correlation coefficient was significantly 
different from 0 . Each test was based on different $\mathrm{N}$ values based on available data for each variable. 'GDP' was deemed redundant and therefore excluded from multivariate analyses. 'Percent of women and men who received HIV testing in the last 12 months and know their results' and 'Percent of HIVpositive new pulmonary smear-positive cases cured' were also excluded since they were poorly populated.

Countries and territories were re-categorized into African (AFR and AFRH) and non-African (CEUR, EEUR, EMR, EME, LAMR, SEAR, and WPR) for bivariate and multivariate analyses. $T$-tests for the linear regression coefficients were used to assess regional, yearly, and HAART coverage differences in the TB/HIV mortality rates from 2006-2008, and similarly for region and HAART coverage in the year 2008 only. Separate multivariate linear regression analyses were then carried out to examine the effect of these variables on TB/HIV co-infection mortality for year 2006-2008 data and year 2008 data only. A total of 122 countries/territories were included for the year 2006-2008 analyses for a total of 346 observations. Observations could have been from year 2006, 2007, or 2008. A total of 114 countries/territories were included in the year 2008 analyses for a total of 114 observations. The primary outcome measure in multivariate analysis was HIV-positive TB mortality rate per 100,000 general population, which was natural log-scaled in order to normalize the distribution. The normality of the outcome was assessed using QQ-plots and Kolmogorov-Smirnov tests, both suggesting that the normal assumption was reasonable. ${ }^{19}$ To standardize the scale of each explanatory variable's data, 'AIDS deaths' data were converted to a rate (number of AIDS deaths over the HIV-positive population). Percent HAART coverage was calculated by dividing the number of persons receiving HAART treatment at the end of 2006, 2007, and 2008 by the total estimated need for HAART in $2007 .{ }^{15} \mathrm{In}$ the 3-year model, repeated measures were accounted for using unstructured correlation matrices in the GENMOD procedure. ${ }^{46}$ Health expenditure units were converted to the format 'current \$100 US per capita'. Model selection was achieved through minimization of the Akaike information criterion (AIC) ${ }^{20}$ and applying the additional constraint that all coefficient $P$-values be below 0.20 .

\section{Results}

All 212 countries included in the analyses had a TB incidence rate, a value for the proportion of HIV among TB incident cases, and a TB/HIV mortality rate for years 2006-2008.

Table 1 is a global summary of all nine regions' HIVassociated average TB mortality and incidence rates per
100,000 people and proportion of HIV among TB incident cases for the years 2006-2008 with low and high uncertainty bounds. Of note, the AFR and AFRH had 13 and 86 HIV-positive TB mortality rates in 2008, respectively. AFRH had a HIV-positive TB mortality rate 2.2 times greater than its HIV-negative TB mortality rate in the same year. AFRH TB/HIV mortality rates were approximately 717 times higher than EME in 2008. Figure 1 shows TB/HIV mortality rates by region in 2008 .

Bivariate analyses of the relationship between the explanatory variables and TB death rates in HIV-positive individuals for the years 2006-2008 revealed that 'AIDS death rate' showed a positive linear relationship with TB/HIV mortality rates over the three years (Pearson's correlation coefficient: 0.350) while 'Government health expenditure', 'GDP', and 'Percentage of men and women who know HIV test results' showed an overall negative linear relationship (Pearson's correlation coefficient: $-0.741,-0.384$, and -0.172 , respectively). All explanatory variables were correlated to $\mathrm{TB} / \mathrm{HIV}$ mortality rates overall $(P<0.05)$.

Table 2 shows the median and interquartile ranges for TB/HIV mortality rates by year and region. All regions' mortality rates differed significantly from each other in each year from 2006 to $2008(P<0.001)$. In those years, African (AFR and AFRH countries) mortality rates were significantly different from non-African countries $(P<0.001)$. The overall median HIV mortality rates in each of those three years also differed significantly from each other $(P=0.002)$.

The unadjusted and adjusted multivariable regression analyses for 122 countries/territories for the years 2006-2008 are reported in Table 3. In unadjusted analyses, region, government health expenditure, proportion of personal health expenditure out of total health expenditure, AIDS death rate, and HAART coverage were significantly associated with HIV-positive TB mortality rates $(P<0.001)$. Countries with HAART coverage $<15 \%$ were associated with a TB/HIV mortality rate 3.6 times higher than countries with $>15 \%$ coverage $(P=0.0004)$. In adjusted analyses, region and government health expenditure were independently associated with TB/ HIV mortality rates $(P<0.05)$. Year was marginally independently associated with TB/HIV mortality rates $(P<0.2)$. Compared with elsewhere in the world, HIVpositive TB mortality rates increased by 29.9 times in African countries $(P<0.0001)$. In 2008, HIV-positive TB mortality rates increased by 1\% compared with 2006 . A US\$100 increase in government health expenditure per 


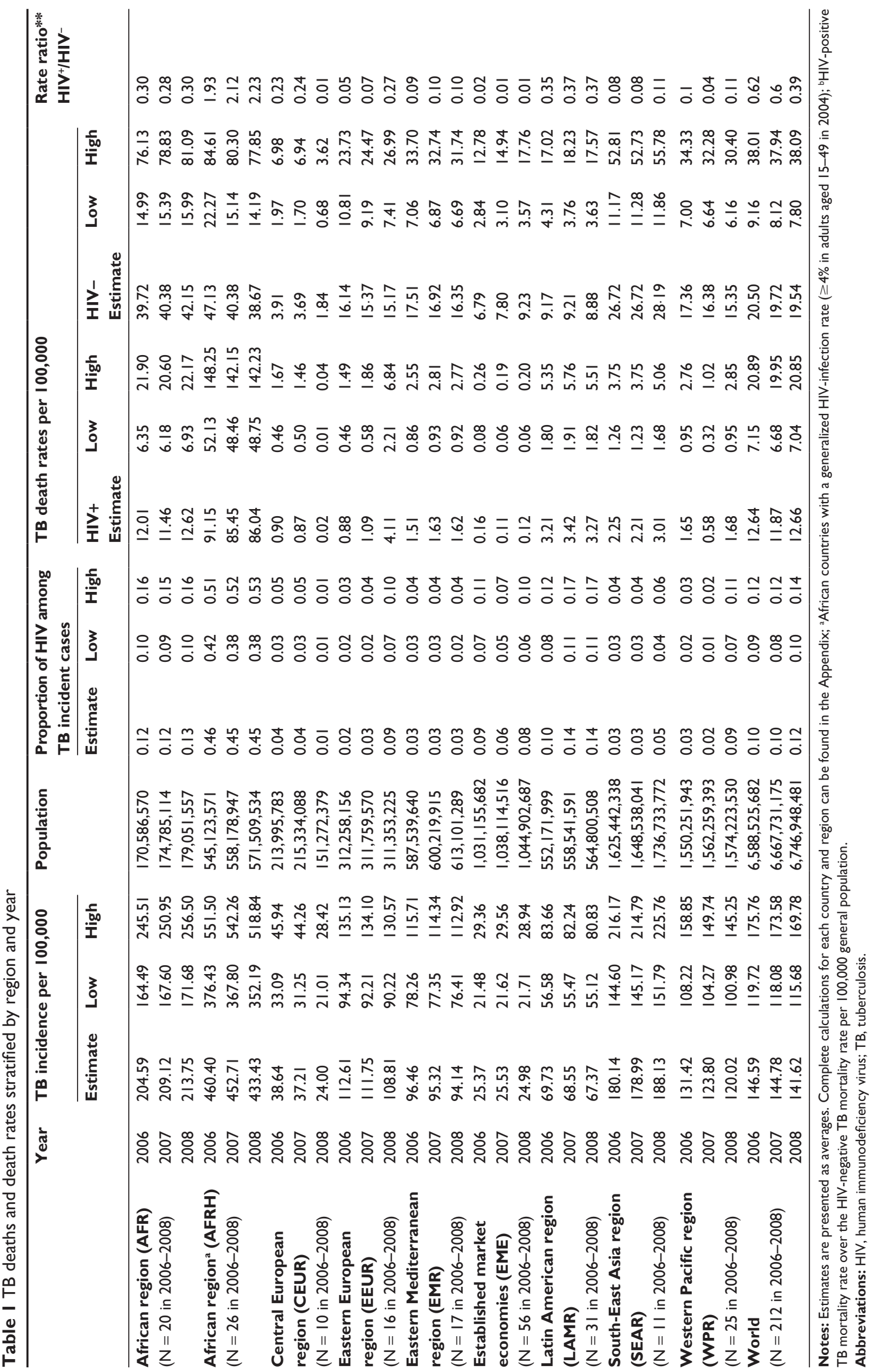




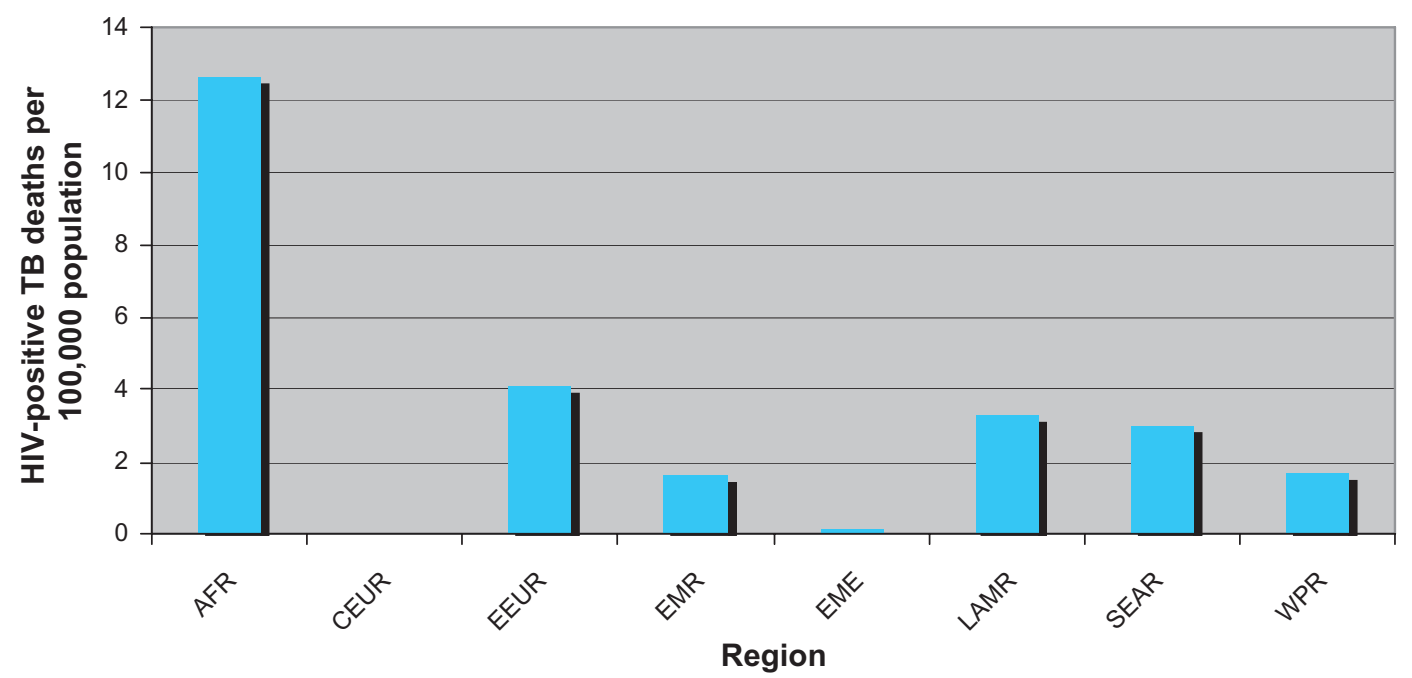

Figure I HIV-positive TB mortality rates by WHO-defined region, excluding African countries with high HIV-infection rate (AFRH), 2008. Africa-countries with low HIV-infection rate (AFR) $(\mathrm{N}=20)$, Central European region (CEUR) $(\mathrm{N}=10)$, Eastern European region (EEUR) $(\mathrm{N}=16)$, Eastern Mediterranean region (EMR) ( $\mathrm{N}=17)$, established market economies (EME) $(N=56)$, Latin American region (LAMR) $(N=31)$, South-East Asia region (SEAR) $(N=1 \mathrm{I})$, and Western Pacific region $(\mathrm{WPR})(\mathrm{N}=25)$. Total $N=2 \mathrm{I} 2$. Abbreviations: HIV, human immunodeficiency virus; TB, tuberculosis; WHO, World Health Organization.

capita was associated with a $0.67(95 \%$ confidence interval [CI]: $0.58,0.76)$ unit increase TB/HIV mortality rates), in other words, every US\$100 dollars spent on health expenditure per capita was associated with $33 \%$ reduction in mortality rates $(P<0.0001)$.
The unadjusted and adjusted multivariable regression analyses for 114 countries/territories in 2008 are reported in Table 4. In unadjusted analyses, region, government health expenditure, the proportion of personal health expenditure out of total health expenditure and the AIDS death rate were

Table 2 A comparison between TB/HIV mortality rates by region and year

\begin{tabular}{|c|c|c|c|c|c|c|c|c|}
\hline \multirow{2}{*}{$\frac{\text { Year }}{\text { Region }}$} & \multicolumn{2}{|c|}{2006} & \multicolumn{2}{|c|}{2007} & \multicolumn{2}{|c|}{2008} & \multicolumn{2}{|c|}{ All years } \\
\hline & $\mathbf{N}^{\mathrm{b}}$ & $\begin{array}{l}\text { Median } \\
\text { (interquartile } \\
\text { range)c }\end{array}$ & $\mathbf{N}^{\mathrm{b}}$ & $\begin{array}{l}\text { Median } \\
\text { (interquartile } \\
\text { range)c }\end{array}$ & $\mathbf{N}^{\mathbf{b}}$ & $\begin{array}{l}\text { Median } \\
\text { (interquartile } \\
\text { range)c }\end{array}$ & $\mathbf{N}^{\mathbf{b}}$ & $\begin{array}{l}\text { Median } \\
\text { (interquartile } \\
\text { range)c }\end{array}$ \\
\hline African region (AFR) & 20 & $7.89(1.25-15.90)$ & 20 & $6.84(0.52-16.37)$ & 20 & $8.02(1.97-18.25)$ & 60 & $7.85(0.70-16.51)$ \\
\hline $\begin{array}{l}\text { African region }{ }^{\mathrm{a}} \\
(\mathrm{AFRH})\end{array}$ & 26 & $61.81(32.30-124.59)$ & 26 & $55.58(31.13-117.34)$ & 26 & $52.60(29.70-104.59)$ & 78 & $55.88(31.13-117.34)$ \\
\hline $\begin{array}{l}\text { Central European } \\
\text { region (CEUR) }\end{array}$ & 10 & $0.00(0.00-0.12)$ & 10 & $0.00(0.00-0.12)$ & 10 & $0.00(0.00-0.03)$ & 30 & $0.00(0.00-0.09)$ \\
\hline $\begin{array}{l}\text { Eastern European } \\
\text { region (EEUR) }\end{array}$ & 16 & $0.39(0.24-I .25)$ & 16 & 0.57 (0.39-I.86) & 16 & $0.48(0.27-2.24)$ & 48 & $0.49(0.29-1.88)$ \\
\hline $\begin{array}{l}\text { Eastern } \\
\text { Mediterranean } \\
\text { region (EMR) }\end{array}$ & 17 & $0.05(0.00-0.23)$ & 17 & $0.07(0.00-0.21)$ & 17 & $0.05(0.00-0.19)$ & 51 & $0.05(0.00-0.23)$ \\
\hline $\begin{array}{l}\text { Established market } \\
\text { economies (EME) }\end{array}$ & 56 & $0.05(0.00-0.12)$ & 56 & $0.03(0.00-0.1 \mathrm{I})$ & 56 & $0.03(0.00-0.10)$ & 168 & $0.03(0.00-0.12)$ \\
\hline $\begin{array}{l}\text { Latin American } \\
\text { region (LAMR) }\end{array}$ & 31 & $\mathrm{I} . \mathrm{I} 3(0.20-2.46)$ & 31 & $1.06(0.003-2.82)$ & 31 & I.I 5 (0.18-2.92) & 93 & I.I3 (0.19-2.66) \\
\hline $\begin{array}{l}\text { South-East Asia } \\
\text { region (SEAR) }\end{array}$ & II & $0.05(0.00-1.38)$ & II & $0.06(0.00-1.6 I)$ & II & $1.36(0.04-3.92)$ & 33 & $0.08(0.04-1.6 I)$ \\
\hline $\begin{array}{l}\text { Western Pacific } \\
\text { region (WPR) }\end{array}$ & 25 & $0.00(0.00-0.25)$ & 25 & $0.00(0.00-0.15)$ & 25 & $0.00(0.00-0.53)$ & 75 & $0.00(0.00-0.27)$ \\
\hline African (AFR + AFRH) & 46 & $28.87(8.33-64.74)$ & 46 & 27.88 (6.78-64.68) & 46 & $25.17(8.03-64.85)$ & 138 & $27.45(8.01-64.74)$ \\
\hline Non-African & 166 & $0.10(0.00-0.76)$ & 166 & $0.08(0.00-0.84)$ & 166 & $0.08(0.00-1.03)$ & 498 & $0.09(0.00-0.85)$ \\
\hline TOTAL (all regions) & 212 & $0.20(0.004-3.33)$ & 212 & $0.15(0.00-3.14)$ & 212 & $0.18(0.00-3.43)$ & 636 & $0.19(0.00-3.25)$ \\
\hline
\end{tabular}

Notes: aAfrican countries with a generalized HIV-infection rate ( $\geq 4 \%$ in adults aged I5-49 in 2004); ${ }^{\mathrm{N}} \mathrm{N}$ represents the number of countries from each region with TB/HIV mortality rates; 'Per 100,000 general population.

Abbreviations: HIV, human immunodeficiency virus; TB, tuberculosis. 
Table 3 Multivariate analyses of factors associated with HIV-positive TB mortality rate (year 2006-2008), N=I22 countries/territories $(\mathrm{N}=1$ I 5 countries in $2006, N=1$ I 7 countries in 2007 , and $N=114$ countries in 2008 ; total of $N=134$ observations)

\begin{tabular}{|c|c|c|c|c|c|}
\hline \multirow[t]{3}{*}{ Variable } & & \multicolumn{4}{|c|}{ HIV-positive TB mortality rate ${ }^{a}$} \\
\hline & & \multicolumn{2}{|c|}{ Unadjusted relative risk } & \multicolumn{2}{|l|}{ Adjusted relative risk } \\
\hline & & Estimate $(95 \% \mathrm{Cl})$ & $P$-value & Estimate $(95 \% \mathrm{Cl})$ & $P$-value \\
\hline \multirow[t]{2}{*}{ Region } & Non-African & I (-) & $<0.0001$ & $\mathrm{I}(-)$ & $<0.0001$ \\
\hline & African & $76.17(44.99-128.98)$ & & $29.93(16.76-53.44)$ & \\
\hline \multirow[t]{3}{*}{ Year } & 2006 & $\mathrm{I}(-)$ & 0.1908 & $\mathrm{I}(-)$ & 0.0919 \\
\hline & 2007 & $0.59(0.27-1.3)$ & & $0.67(0.38-1.18)$ & \\
\hline & 2008 & $0.9 \mathrm{I}(0.4 \mathrm{I}-2.03)$ & & I.0I (0.57-I.79) & \\
\hline $\begin{array}{l}\text { Government health expenditure } \\
\text { at average exchange rate } \\
\text { (logarithm of, US } \$ 100 \text { per capita) }\end{array}$ & & $0.45(0.39-0.5 \mathrm{I})$ & $<0.0001$ & $0.67(0.58-0.76)$ & $<0.0001$ \\
\hline Personal health expenditure & & $1.05(1.03-1.07)$ & $<0.0001$ & Not included in final model & \\
\hline \multicolumn{6}{|l|}{ as a percentage of total } \\
\hline \multicolumn{6}{|l|}{ health expenditure (\%) } \\
\hline AIDS death rate (logarithm of) & & $1.34(1.14-1.57)$ & 0.0003 & Not included in final model & \\
\hline \multirow[t]{2}{*}{ HAART coverage $(\%)$} & $<15 \%$ & $3.6(1.76-7.35)$ & 0.0004 & Not included in final model & \\
\hline & $\geq 15 \%$ & $\mathrm{I}(-)$ & & & \\
\hline
\end{tabular}

Note: aNatural log-scaled HIV-positive TB mortality rate.

Abbreviations: AIDS, acquired immunodeficiency syndrome; $\mathrm{Cl}$, confidence interval; HAART, highly active antiretroviral therapy; HIV, human immunodeficiency virus; TB, tuberculosis.

significantly associated with HIV-positive TB mortality rates $(P<0.0001)$.

In adjusted analyses, region and government health expenditure were independently associated with TB/HIV mortality rates $(P<0.05)$. The proportion of personal health expenditure out of total health expenditure was marginally independently associated with TB/HIV mortality rates $(P<0.2)$. Compared with elsewhere in the world, HIV-positive TB mortality rates were higher by 28.9 times in African countries $(P<0.0001)$. Increasing the proportion of personal health expenditure out of total health expenditure was associated with a $2 \%$ increase in TB/HIV mortality rates $(P=0.1168)$. A one hundred dollar increase in health expenditure per capita was associated with a $0.73(95 \%$ CI: $0.56,0.95)$ unit increase in TB/HIV mortality rates, meaning, every one hundred US dollars spent on government health expenditure per capita was associated with a $27 \%$ reduction in mortality rates $(P<0.05)$.

\section{Discussion}

Our results indicate that in 2008, the highest TB mortality rates among HIV-positive individuals were in Africa, followed by the EEUR, LAMR, and SEAR. Multivariate analyses confirmed that Africa had significantly higher TB/ HIV mortality rates than non-African regions. Our adjusted multivariate analysis for the year 2008 revealed an association between government health expenditure and lower

Table 4 Multivariate analyses of factors associated with 2008 HIV-positive TB mortality rate, $\mathrm{N}=$ II 4 countries/territories

\begin{tabular}{|c|c|c|c|c|c|}
\hline \multirow[t]{3}{*}{ Variable } & & \multicolumn{4}{|c|}{ HIV-positive TB mortality rate ra $^{a}$} \\
\hline & & \multicolumn{2}{|c|}{ Unadjusted relative risk } & \multicolumn{2}{|c|}{ Adjusted relative risk } \\
\hline & & Estimate $(95 \% \mathrm{Cl})$ & $P$-value & Estimate $(95 \% \mathrm{Cl})$ & $P$-value \\
\hline \multirow[t]{2}{*}{ Region } & Non-African & I (-) & $<0.0001$ & $\mathrm{I}(-)$ & $<0.0001$ \\
\hline & African & $68.17(30.26-153.57)$ & & $28.88(|1.7|-7 \mid .2 I)$ & \\
\hline Government health expenditure & & $0.44(0.36-0.53)$ & $<0.000$ I & $0.73(0.56-0.95)$ & 0.0178 \\
\hline \multicolumn{6}{|l|}{ at average exchange rate (logarithm } \\
\hline \multicolumn{6}{|l|}{ of, US\$I00 per capita) } \\
\hline Personal health expenditure as a percentage & & $1.06(1.03,1.08)$ & $<0.0001$ & $1.02(1.00-1.05)$ & 0.1168 \\
\hline \multicolumn{6}{|l|}{ of total health expenditure (\%) } \\
\hline AIDS death rate (logarithm of) & & $3.72(2.07-6.69)$ & $<0.0001$ & \multicolumn{2}{|c|}{ Not included in final model } \\
\hline \multirow[t]{2}{*}{ HAART coverage (\%) } & $<15 \%$ & $1.47(0.5-4.3)$ & 0.9548 & Not included in final $n$ & \\
\hline & $\geq 15 \%$ & $\mathrm{I}(-)$ & & & \\
\hline
\end{tabular}

Note: aNatural log-scaled HIV-positive TB mortality rate.

Abbreviations: AIDS, acquired immunodeficiency syndrome; $\mathrm{Cl}$, confidence interval; HAART, highly active antiretroviral therapy; HIV, human immunodeficiency virus; TB, tuberculosis. 
TB/HIV mortality rates. Personal health expenditure was associated with higher TB/HIV mortality rates.

Regions known to have a high HIV prevalence were identified to have proportionally higher HIV-positive TB death rates in our results. ${ }^{5}$ High TB incidence and mortality among HIV-positive individuals in the African region lends support to our findings that African countries bear the highest burden from both diseases. ${ }^{1,8,9}$ However, non-African regions containing countries/territories known to have a high-burden of TB also had elevated TB/HIV mortality rates, suggesting that this burden is not limited to Africa. ${ }^{1}$ The ratio $(>1)$ of HIV-positive to HIV-negative TB mortality rates in the AFRH confirms the greater mortality risk in TB/HIV co-infected individuals.

Our study revealed that increasing per capita government health expenditure might lower TB/HIV mortality rates. Since developing regions in the world bear the highest TB/ HIV burden, these regions would benefit the most from an increase in financial resources. There is a critical need for increased collaboration between HIV and TB management due to the overlapping impact of the diseases. For example, provider-initiated HIV-testing for TB patients in developing regions is poorly implemented, ${ }^{21}$ even though this has been regarded as a key entry point into ARV therapy for undiagnosed individuals. ${ }^{22-25}$ Furthermore, the "Three I's" principle of Isoniazid preventative therapy, Intensified TB case finding, and Infection control is widely viewed as an effective TB management strategy in HIV-infected individuals. ${ }^{26-30}$ However, a lack of formal resources has compromised these initiatives, including basic laboratory services that detect HIV-associated TB, particularly smear-negative disseminated and drug resistant forms. ${ }^{31,32}$ Before strategy becomes common practice, developing infrastructure and relevant operational details to supplement policy can ensure service delivery to individuals in need. ${ }^{33}$

In contrast, our findings also showed that increasing the proportion of personal health expenditure out of total health expenditure might increase TB/HIV mortality rates. Research on treatment-seeking behavior in the African setting revealed a lower proportion of patients actively seeking health care prior to requiring mandatory hospitalization when out-of-pocket payments were required. ${ }^{34}$ Other studies have shown that out-of-pocket payments increase the likelihood of patients self-medicating or delaying treatment until their condition worsens. ${ }^{35,36}$ This evidence suggests that countries with the highest TB/HIV burden may need to increase public health care expenditure.

TB/HIV health care services have been favored for expansion, ${ }^{33}$ such as provider-initiated HIV testing and elements of the "Three I's" program which have been evaluated for cost-effectiveness. ${ }^{37,38}$ Recently, increasing HAART coverage combined with early ARV treatment has been championed as a strategy to decrease TB incidence. ${ }^{39}$ Yet, national budgets in high TB-burdened countries have allocated limited funds to support TB/HIV collaborations. ${ }^{3}$ When examining the resources dedicated to each disease separately, HIV/AIDS health expenditure has expanded dramatically compared with other related sectors. ${ }^{40}$ In stark contrast, financial resources dedicated to TB have been a fraction of that, ${ }^{3,40}$ allocated mostly to DOTS (directly observed treatment, short-course), the recommended strategy for TB control. ${ }^{41}$ Yet, DOTS has been questioned as an effective method for controlling the disease. ${ }^{25,42}$ HAART coverage was significantly associated with lower TB/HIV mortality rates in bivariate analysis (2006-2008), but was not independently associated with these same rates in our multivariate model. This suggests that HAART coverage is dependent on public health expenditure. Given that HIV/ AIDS and TB are both devastating infectious diseases, the striking disparity in TB to HIV funding not only calls for greater financial resources dedicated to combat TB, but also, more specifically, investment in programs such as widespread HAART distribution that may enhance treatment for both diseases.

There are limitations to consider with this analysis. Since our primary source of data was from WHO, our analyses relied on estimates based on their calculation methodology. Their source data were based on a dearth of documented mortality cases reported to them from each country/territory. ${ }^{1-3,18}$ In a cohort study and literature review assessing the burden of TB, similar limitations may have led to an underestimation of TB deaths among the HIV-positive population. ${ }^{4,43}$ In addition, many countries that do report vital statistics do not subcategorize an HIV death as being TB-associated. Moreover, TB incidence, a mortality model input, is not directly measureable and instead relies on obtaining expert opinion. No country has ever completed a national survey of TB incidence nor established criteria for verifying the reliability of a country's routine TB surveillance system. However, continued improvements have been made to WHO data collection methodologies from years past, such that the rise of HIV-testing in TB patients has contributed to a substantial increase in the number of reported TB deaths associated with HIV. ${ }^{3,44,45}$ Additionally, not all countries/territories from a region may share the same mortality burden, since those with a high rate of TB/HIV mortality would have skewed regional average mortality rates. 
A lack of comprehensive and complete country data on health care resources limited our bivariate and multivariate analyses. Since our sample size was restricted to countries with data available for every explanatory variable, our findings may not be applicable to all regions. Additionally, we were limited by a lack of recent statistics. For example, ARV treatment coverage for year 2008 was calculated using statistics from 2007 while health expenditure for 2008 was extrapolated from 2006 data. These findings underscore the need for more comprehensive and updated global health statistics.

Our findings on the global burden of TB mortality in HIVpositive individuals call for additional investigation in this area. This study is unique because it relates the worldwide burden of HIV-related TB mortality to the latest publicly available health indicator data. We found incomplete national health indicator data which limits thorough and ideal global analyses. Nevertheless, our study encourages further discussion on the issue of reducing these diseases' death toll, especially in developing nations. Finally, it is clear that there is an urgent need for increased public funding toward TB health care services that have long-term effectiveness in high HIVprevalence settings. This funding should be directed towards developing widespread HAART distribution programs.

\section{Contributors}

CG Au-Yeung, A Anema, JSG Montaner, RS Hogg, and EJ Mills designed the study. CG Au-Yeung, S Kanters, E Ding, and P Glaziou performed the analyses. CG Au-Yeung prepared the first draft of the manuscript. EJ Mills supervised the study. All authors revised the manuscript critically for important intellectual content. All authors approved the final version for publication.

\section{Acknowledgments}

Eric Druyts, Hazim Bakir Timimi, Katherine Muldoon, and Nicholas Antipenkov are thanked for their research assistance. Svetlana Draskovic and Kelly Hsu are thanked for their administrative assistance.

\section{Disclosure}

RS Hogg has held grant funding from the National Institutes of Health, Canadian Institutes of Health Research National Health Research Development Program, and Health Canada. He has also received funding from Agouron Pharmaceuticals Inc., Boehringer Ingelheim Pharmaceuticals Inc., Bristol-Myers Squibb, GlaxoSmithKline, and Merck Frosst Laboratories for participating in continued medical education programs. JSG Montaner has received grants from, served as an ad hoc advisor to, or spoken at various events sponsored by Abbott, Argos Therapeutics, Bioject Inc., Boehringer Ingelheim, BMS, Gilead Sciences, GlaxoSmithKline, Hoffmann-La Roche, Janssen-Ortho, Merck Frosst, Pfizer, Schering, Serono Inc., TheraTechnologies, Tibotec, and Trimeris. He has also held grant funding from the Canadian Institutes of Health Research and National Institutes of Health. He has also received funding for research and continuing medical education programs from a number of pharmaceutical companies including Abbott, Boehringer Ingelheim, and GlaxoSmithKline. EJ Mills is supported by a Canada Research Chair in Global Health from Canadian Institutes of Health Research and unrestricted research support from Pfizer Canada Inc.

\section{References}

1. WHO. Global Tuberculosis Control: Surveillance, Planning, Financing: WHO report 2007. Geneva, Switzerland: World Health Organization; 2007. http://www.who.int/tb/publications/global_report/2007/pdf/full. pdf. Accessed Jan 42009.

2. WHO. Global Tuberculosis Control: Surveillance, Planning, Financing: WHO report 2008. Geneva, Switzerland: World Health Organization; 2008. http://www.who.int/tb/publications/global_report/2008/pdf/ fullreport.pdf. Accessed Jan 42009.

3. WHO. Global Tuberculosis Control: Surveillance, Planning, Financing: WHO report 2009. Geneva, Switzerland: World Health Organization, 2009. http://www.who.int/tb/publications/global_report/2009/pdf/ full_report.pdf. Accessed Apr 42009.

4. Dye C, Scheele S, Dolin P, Pathania V, Raviglione MC. Global burden of tuberculosis: estimated incidence, prevalence, and mortality by country. WHO Global Surveillance and Monitoring Project. JAMA. 1999;282:677-686.

5. UNAIDS. Report on the Global AIDS Epidemic. Geneva, Switzerland: Joint United Nations Programme on HIV/AIDS, 2008. http://www. unaids.org/en/KnowledgeCentre/HIVData/GlobalReport/2008/2008_ Global_report.asp. Accessed Jan 42009.

6. Braitstein PMA, Nyandiko W, Vreeman R, et al. The clinical burden of tuberculosis among human immunodeficiency virus-infected children in western Kenya and the impact of combination antiretroviral treatment. Pediatr Infect Dis J. 2009;28:626-632.

7. Saraceni V, King BS, Cavalcante SC, et al. Tuberculosis as primary cause of death among AIDS cases in Rio de Janeiro, Brazil. Int J Tuberc Lung Dis. 2008;12:769-772.

8. Elliott AM, Halwiindi B, Hayes RJ, et al. The impact of human immunodeficiency virus on mortality of patients treated for tuberculosis in a cohort study in Zambia. Trans R Soc Trop Med Hyg. 1995;89: 78-82.

9. Moore D, Leichty C, Ekwaru P, et al. Prevalence, incidence and mortality associated with tuberculosis in HIV-infected patients initiating antiretroviral therapy in rural Uganda. AIDS. 2007;21:713-719.

10. Kang'ombe CT, Harries AD, Ito K, et al. Long-term outcome in patients registered with tuberculosis in Zomba, Malawi: mortality at 7 years according to initial HIV status and type of TB. Int J Tuberc Lung Dis. 2004;8:829-836.

11. El-Sony AI, Khamis AH, Enarson DA, Baraka O, Mustafa SA, Bjune G. Treatment results of DOTS in 1797 Sudanese tuberculosis patients with or without HIV co-infection. Int J Tuberc Lung Dis. 2002;6: 1058-1066.

12. Connolly C, Davies, GR, Wilkinson, D. Impact of the human immunodeficiency virus epidemic on mortality among adults with tuberculosis in rural South Africa, 1991-1995. Int J Tuberc Lung Dis. 1998;2: 919-925. 
13. Daniel OJ, Alausa OK. Treatment outcome of TB/HIV positive and TB/HIV negative patients on directly observed treatment, short course (DOTS) in Sagamu, Nigeria. Niger J Med. 2006;15: 222-226.

14. Khan M, Pillay T, Moodley JM, Connolly CA; for the Durban Perinatal TB HIV-1 Study Group. Maternal mortality associated with tuberculosis-HIV-1 co-infection in Durban, South Africa. AIDS. 2001;15:1857-1863.

15. World Health Organization (WHO), Joint United Nations Programme on HIV/AIDS (UNAIDS), United Nations Children's Fund (UNICEF). Towards Universal Access: Scaling up priority HIV/AIDS interventions in the health sector. Progress Report 2009. http://www.who.int/hiv/ pub/2009progressreport/en/. Accessed Dec 272009.

16. United Nations. UNDATA: a world of information. United Nations Statistics Division, 2009. http://data.un.org. Accessed Jan 4 2009.

17. World Health Organization (WHO). World Health Statistics 2009. http:// www.who.int/whosis/whostat/EN_WHS09_Full.pdf. Accessed Dec 27 2009.

18. WHO. Global Tuberculosis Control: Surveillance, Planning, Financing. WHO report 2009 update. Geneva, Switzerland: World Health Organization; 2009. http://www.who.int/tb/publications/global_report/2009/ update/tbu_9.pdf. Accessed Nov 112009.

19. Refaat M. Data Preparation for Data Mining using SAS. San Francisco, CA: Morgan Kaufmann; 2007.

20. Akaike H. A new look at the statistical model identification. IEEE Trans Automat Contr. 1974;AC-19:716-723.

21. WHO. Global Tuberculosis Control: Surveillance, Planning, Financing. Geneva, Switzerland: WHO; 2006. WHO/HTM/TB/2006.362.

22. Godfrey-Faussett P, Maher D, Mukadi YD, Nunn P, Perriens J, Raviglione M. How human immunodeficiency virus voluntary testing can contribute to tuberculosis control. Bull World Health Organ. 2002;80:939-945.

23. Reid A, Scano F, Getahun H, et al. Towards universal access to HIV prevention, treatment, care, and support: the role of tuberculosis/HIV collaboration. Lancet Infect Dis. 2006;6:483-495.

24. Creek TL, Ntumy R, Seipone K, et al. Successful introduction of routine opt-out HIV testing in antenatal care in Botswana. J Acquir Immune Defic Syndr. 2007;45:102-107.

25. Harries AD, Boxshall M, Phiri S, et al. Providing HIV care for tuberculosis patients in sub-Saharan Africa. Int J Tuberc Lung Dis. 2006;10: 1306-1311.

26. WHO. TB/HIV Facts 2008. Geneva, Switzerland: World Health Organization; 2008. http://www.stoptb.org/wg/tb_hiv/assets/documents/ Fact $\% 20$ sheet $\% 20$ HIV $\% 20$ TB $\% 20$ for $\% 20 I A S \% 20$ FINAL.pdf. Accessed Feb 42009.

27. Heller RF, Gemmell I, Edwards R, Buchan I, Awasthi S, Volmink JA. Prioritising between direct observation of therapy and case-finding interventions for tuberculosis: use of population impact measures. $B M C$ Med. 2006;4:35.

28. Gupta A, Nayak U, Ram M, et al. Postpartum tuberculosis incidence and mortality among HIV-infected women and their infants in Pune, India, 2002-2005. Clin Infect Dis. 2007;45:241-249.
29. World Health Organization Global Tuberculosis Programme. Policy Statement on Preventive Therapy Against Tuberculosis in People Living with $H I V$. Geneva, Switzerland: World Health Organization; 1998. http://www. emro.who.int/stb/media/pdf/tbhivpolicy.pdf. Accessed Apr 42009.

30. WHO. Tuberculosis Care with TB-HIV Co-management: Integrated Management Of Adolescent And Adult Illness. Geneva, Switzerland: World Health Organization; 2007. http://www.who.int/hiv/pub/imai/ TB_HIVModule23.05.07.pdf. Accessed Apr 42009.

31. Ishengoma DR, Rwegoshora RT, Mdira KY, et al. Health laboratories in the Tanga region of Tanzania: the quality of diagnostic services for malaria and other communicable diseases. Ann Trop Med Parasitol. 2009;103:441-453.

32. Dowdy DW, Lourenco MC, Cavalcante SC, et al. Impact and costeffectiveness of culture for diagnosis of tuberculosis in HIV-infected Brazilian adults. PLoS. 2008;3:1-8.

33. Vitoria M, Granich R, Gilks CF. The global fight against HIV/AIDS, tuberculosis, and malaria: current status and future perspectives. Am J Clin Pathol. 2009;131:844-848.

34. Castillo-Riquelme M, Mcintyre D, Barnes K. Household burden of malaria in South Africa and Mozambique: is there a catastrophic impact? Trop Med Int Health. 2008;13:108-122.

35. Mugisha F, Kouyate B, Gbangou A, et al. Examining out-of-pocket expenditure on health care in Nouna, Burkina Faso: implications for health policy. Trop Med Int Health. 2008;7:187-196.

36. Chuma JM, Thiede M, Molyneux CS. Rethinking the economic costs of malaria at the household level: evidence from applying a new analytical framework in rural Kenya. Malaria J. 2006;5:14.

37. Terris-Prestholt F, Kumaranayake L, Ginwalla R, et al. Integrating tuberculosis and HIV services for people living with HIV: costs of the Zambian ProTEST initiative. Cost Eff Resour Alloc. 2008;6:2.

38. Kumaranayake L, Muvira A, Chimzizi R, et al. Economic analysis of delivering integrated TB and HIV services: the Malawi ProTEST project [abstract]. Int Conf AIDS. 2004:TuPeD5214.

39. Williams BG, Dye C. Antiretroviral drugs for tuberculosis control in the era of HIV/AIDS. Science. 2003;12:1535-1537.

40. Ravishankar N, Gubbins P, Cooley RJ, et al. Financing of global health: tracking development assistance for health from 1990 to 2007. Lancet. 2009;373:2113-2124.

41. WHO. Interim Policy on Collaborative TB/HIV Activities. Geneva, Switzerland: Stop TB Department and Department of HIV/AIDS; 2004. http://whqlibdoc.who.int/hq/2004/who_htm_tb_2004.330.pdf Accessed Apr 42009.

42. Idemyor V. HIV and tuberculosis coinfection: inextricably linked liaison. J Natl Med Assoc. 2007;99:1414-1419.

43. Corbett EL, Watt CJ, Walker N, et al. The growing burden of tuberculosis: global trends and interactions with the HIV epidemic. Arch Intern Med. 2003;163:1009-1021.

44. Zarocostas J. WHO revises upwards estimated number of TB deaths associated with HIV. BMJ. 2009;338:b1253.

45. WHO. Treating 3 Million by 2005: Making it Happen. Geneva, Switzerland: World Health Organization; 2003.

46. Liang K, Seger S. Longitudinal data analysis using generalized linear models. Biometrika. 1986;73:13-22.
Clinical Epidemiology

\section{Publish your work in this journal}

Clinical Epidemiology is an international, peer-reviewed, open access journal focusing on disease and drug epidemiology, identification of risk factors and screening procedures to develop optimal preventative initiatives and programs. Specific topics include: diagnosis, prognosis, treatment, screening, prevention, risk factor modification, systematic

\section{Dovepress}

reviews, risk \& safety of medical interventions, epidemiology \& biostatical methods, evaluation of guidelines, translational medicine, health policies \& economic evaluations. The manuscript management system is completely online and includes a very quick and fair peer-review system, which is all easy to use. 